\title{
AMPLIANDO A SALA DE AULA: O USO DE METODOLOGIAS ATIVAS NA MONITORIA ACADÊMICA
}

\author{
ENLARGING THE CLASSROOM: USING ACTIVE METHODOLOGIES IN \\ ACADEMIC MONITORING
}
Francisco William Melo de Sousa, Jessica Ketleen Caetano Lopes, Maria Luisa Damasceno Silva, Maria do Socorro Melo Carneiro, Lycélia da Silva Oliveira

Universidade Estadual Vale do Acaraú - UVA

\begin{abstract}
Report the activities developed through active methodologies in the academic monitoring of the undergraduate nursing course. This is a descriptive experience-type study with a qualitative approach, elaborated from experiences in the academic monitoring of the Primary Health Care II module, component of the curricular grid of the undergraduate nursing degree course, at Vale do Acaraú State University, during the period. from April to August 2019. The approach of the Unified Health System, Family Health Strategy, social participation, family assessment tools and the use of active methodologies in the monitoring meetings allowed the effective construction of collective learning, enabled the exchange of knowledge, experiences and knowledge that enriched academic and professional training. Monitoring as a program of initiation to teaching provides academic improvement in the university environment, allowing the student to approach the profession of being a teacher, above all, enables the development of communication and social skills and abilities.
\end{abstract}

Keywords: Primary Health Care, Higher Education, Monitoring.

\section{Resumo}

Relatar as atividades desenvolvidas por meio de metodologias ativas na monitoria acadêmica do curso de graduação em enfermagem. Estudo descritivo, do tipo relato de experiência, de abordagem qualitativa, elaborado a partir de vivências na monitoria acadêmica do módulo Atenção Primária à Saúde II, componente da grade curricular do curso de graduação em enfermagem bacharelado, da Universidade Estadual Vale do Acaraú, no período de abrila agosto de 2019.A abordagem das temáticas Sistema Único de Saúde, Estratégia Saúde da Família, participação social, ferramentas de avaliação familiar e o uso de metodologias ativas nos encontros de monitoria oportunizaram a construção efetiva do aprendizado coletivo, possibilitaram a troca de conhecimentos, de experiências e saberes que enriqueceram a formação acadêmica e profissional. A monitoria enquanto programa de iniciação à docência proporciona o aprimoramento acadêmico no ambiente universitário, permitindo ao estudante aproximação do ofício de ser professor, sobretudo,oportuniza o desenvolvimento de competências e habilidades comunicacionais $e$ sociais.

Palavras chave: Atenção Primária à Saúde, Ensino Superior, Monitoria. 


\section{Introdução}

A monitoria consiste em uma ferramenta de aprimoramento acadêmico, em que proporciona ao aluno-monitor a ampliação dos conhecimentos, a integração entre teoria e prática, a revisão dos conteúdos, esclarecimento de dúvidas, e, sobretudo, permite a aproximação com o exercício da docência ${ }^{1}$.

A Universidade Estadual Vale do Acaráu (UVA) por meio da Pró-Reitoria de Ensino e Graduação (PROGRAD), estimula as atividades de monitoria, inserindo-as no Programa de Iniciação à Docência, que visa fortalecer a cooperação entre corpo docente e discente, além de proprocionar ao acadêmico a oportunidade de se preparar para atividades de ensino. $\mathrm{Na}$ instituição, anualmente, é realizado o Encontro de Iniciação à Docência, momento no qual ocorre a consolidação e a socialização dos saberes e experiências desenvolvidas no programa de monitoria acadêmica².

Diante da importância das atividades de monitoria na formação acadêmica, e compreendendo que essa deve ser aplicada tendo em vista uma atuação que envolva o uso de estratégias didáticas que facilitem o aprendizado e tornem este mais dinâmico, é fundamental operacionalizar o ensino com artifícios que valorizem o conhecimento e a troca de saberes entre os envolvidos.

Dessa maneira, torna-se significativamente relevante o uso das Metodologias Ativas, que são entendidas como estratégias educativas que possibilitam ao estudante a construção do conhecimento por meio de um processo de ensino e aprendizagem crítico e reflexivo, bem como estimula a autonomia e a participação produtiva no aprendizado ${ }^{3}$. Assim, a monitoria acadêmica desenvolvida por meio destes recursos pedagógicos permite que o estudante seja participante ativo da sua formação.

Diante disso, os temas que envolvem a Atenção Primária à Saúde (APS), especificamente, o Sistema Único de Saúde (SUS), Estrátegia Saúde da Família (ESF), a participação social em saúde e as ferramentas de avaliação familiar, dentro do escopo de atuação multiprofissional, em especial dos acadêmicos de enfermagem, são considerados conteúdos densos e complexos, o que torna o processo de ensino-aprendizagem cansativo. Nesta perspectiva, a incoporação de metodologias ativas facilitar a compreensão dos assuntos, proporcionando aos discentes 0 aprendizado de forma dinâmica, objetiva e criativa.

Nesse contexto, ao se ponderar a relevância do processo formativo na graduação baseado em metodologias diferenciadas que oportunizem aprendezido efetivo, torna-se relevante apresentar experiências como esta, visto o impacto no desenvolvimento e aprimoramento na formação, sobretudo, na socialização de estratégias e ferramentas de cunho pedagógico que auxiliam no processo educacional. Portanto, objetivou-se relatar as atividades desenvolvidas por meio de metodologias ativas na monitoria acadêmica do curso de graduação em enfermagem.

\section{Metodologia}

Trata-se de um estudo descritivo, do tipo Relato de Experiência, de abordagem qualitativa, referente as atividades de monitoria universitária realizada no módulo Atenção Primária à Saúde II (APS II) do curso de Enfermagem da UVA, em Sobral-Ceará, durante o semestre letivo 2019.1.

O módulo Atenção Primária à Saúde é ofertado de forma transversal, do primeiro ao sétimo semestre do curso, ou seja, a cada período são abordadas temáticas específicas que envolvem a Atenção Primária. O APS II é ofertado durante o segundo semestre, no qual os temas discutidos são: organização dos serviços ofertados no SUS, a ESF, ações de territorialização em saúde, participação social e ferramentas de avaliação familiar ${ }^{4}$.

Os encontros de monitoria foram realizados no Centro de Ciência da Saúde (CCS) no contraturno, haja vista que o curso de enfermagem é de modalidade integral. Os momentos ocorriam, quizenalmente, pois, as aulas eram intercaladas entre teóricas e vivências nas Unidades Básicas de Saúde (UBS) de Sobral, Ceará, e tinham duração de duas horas, com a participação de 24 acadêmicos de enfermagem. Ao todo foram realizados cinco encontros em sala de aula.

\section{Resultados e Discussão}

Inicialmente, para realização dos encontros de monitoria, fez-se o planejamento das atividades junto à professora coordenadora do módulo, no qual levou-se em consideração as metodologias ativas como estratégias 
facilitadoras no processo de assimilação e socialização do conhecimento. Este momento ocorreu no início do semetre, ocasião na qual os monitores apresentaram as proprostas de atividades e metodologias educacionais que poderiam ser utilizadas para discussão das temáticas do módulo em estudo, e a partir disso, foram selecionadas aquelas pertinentes $e$ aplicavéis para os encontros de monitoria.

Nesse contexto, a discussão sobre o SUS e a ESF se deu por meio da atividade "Caixa dos Saberes". Para realização desse momento, utilizou-se uma caixa decorada, 14 fichas com questões discussivas e objetivas sobre as temáticas em estudo e uma caixa de som. A atividade tinha como objetivo revelar o conhecimento dos acadêmicos e discurtir os assuntos já estudados. Em roda, os alunos foram estimulados a retirar da caixa uma pergunta ao passo que era dada pausa na música; a partir da questão sorteada, dialogava-se a respeito do assunto, sobre o qual os discentes compartilhavam seus conhecimentos apreendidos em aulas anteriores.

A atividade desenvolvida por meio dessa metodologia proporcionou um momento de revisão dos conteúdos em estudo, bem como oportunizou aos alunos a participação colaborativa na discussãos dos assuntos. A maioria dos estudantes acertaram as setenças selecionadas, principalmente, as referentes à ESF. O momento em roda, proporcionou a interação e troca de saberes entre monitores e discentes, de forma colaborativa e agradável. A estratégia da realização da monitoria por meio da roda de conversa remete à ideia da aproximação dos estudantes para ouvir o próximo com atenção. Nesse contexto, essa abordagem é uma possibilidade metodológica em que os estudantes estabelecem um espaço de diálogo e interação, bem como uma comunicação produtiva que amplia a construção do aprendizado 5 .

Outra temática abordada foi a territorialização em saúde, assunto que foi trabalhado a partir da aplicação de um "Simulado Interativo", conduzido por meio da metodologia Team Based Learn (TBL). O TBL é método educacional que consiste na aprendizagem em equipe, propondo aos estudantes uma aprendizagem ativa e o desenvolvimento de habilidades relacionadas ao trabalho colaborativo em grupo 6 . Nesse processo, o educando passa a ser o agente principal na aprendizagem e o educador o agente mediador da aquisição do conhecimento.

O "Simulado Interativo" foi composto de 10 questões objetivas retiradas de provas de processos seletivos de concursos e residências em saúde. A aplicação se deu em três momentos e contou com público de 18 estudantes e duração de duas horas. No primeiro momento os estudantes responderam 0 simulado individualmente; no segundo momento, os discentes foram divididos em trios para, em grupo, realizarem novamente a leitura e a discussão das questões para obter consenso nas respostas; por fim, no terceiro momento foi realizado o debate em conjunto das questões do simulado para revisão e esclarecimento de dúvidas a respeito do assunto.

A abordagem dessa temática por meio desse método foi inovadora para turma, pois os acadêmicos não a conheciam, além disso, proporcinou a preparação para avaliação parcial do módulo que seria aplicada seguindo a metodologia TBL. O trabalho em equipe, proprocionou um apredizado coletivo, como também a socialização dos saberes e a troca de experiências.

A partir da aplicação do simulado, pode-se observar que os discentes, ao realizarem o simulado de forma individual, tiveram uma pontuação entre seis a nove questões, todavia, em grupo, pontuaram entre nove a dez questões, evidenciando que $o$ processo ensinoaprendizagem através de atividades em grupo facilitou a troca de conhecimentos, assim como fortaleceu as potencialidades dos estudantes, oportunizando solucionar as dificuldades.

A abordagem sobre participação social, isto é, a participação da comunidade no SUS regulamentada pela lei $8142 / 90$, seu deu através do recurso de Mapas Mentais, ou seja, por meio da contrução de esquemas com os principais conceitos sobre a temática. $\mathrm{Na}$ atividade, os alunos comprenderam sobre o conceito de conferência e conselho de saúde, sua organização e composição, os recursos alocados nos serviços de saúde. Além disso, utilizou-se a rede social WhatsApp, como ferramenta de socialização de materiais sobre o assunto em estudo. Nessa perspectiva, o WhatsApp constituiu-se como um espaço facilitador para discussão do assunto, proporcionando a 
organização dos conteúdos de interesse para suscitar a participação produtiva dos estudantes ${ }^{7}$.

Outro assunto trabalhado consistiu nas ferramentas de avaliação familiar na APS. Durante o encontro, o tema foi abordado por meio de vídeos educativos e estudo de casos clínicos relacionados às ferramentas de avaliação familiar, como genograma e ecomapa. O genorama é uma representação gráfica, elaborado por meio de símbolos que possibilita comprrender a composição familar, em pelo menos, três gerações. Já o ecomapa é um diagrama das relações da família com a comunidade, ou seja, com os equipamentos de apoio e utilizados, como instituições educacionais, UBS, igrejas, associações comunitárias e pessoas da comunidade ${ }^{8}$.

Os videos utilizados tinham duração de 10 minutos e abordavam o conceito e aplicação dessas ferramentas no âmbito da APS. O uso de casos clínicos foi escolhido por compor uma estratégia de ensino humanística e problematizadora, por proporcionar momentos de discussões acerca do conhecimento teóricoprático, do planejamento da assistência e da avaliação dos resultados, estimulando o pensamento crítico-reflexivo na tomada de decisões ${ }^{9}$.

Ao final do semestre, fez-se o encerramento do módulo, em que foi aplicado um questionário com questões objetivas para avaliação das metodologias, desempenho do docente nas aulas e atuação dos monitores. Além disso, realizou-se a dinâmica dos balões coloridos, ou seja, cada estudante recebeu um balão e um pedaço de papel no qual escreveram sentimentos, experiências e/ou contribuições do módulo para sua formação. Feito isso, ao som de uma música, os alunos foram desafiados a jogar os balãos sem deixá-los cair até o termino da canção. O objetivo da atividade nesse primeiro momento foi mostrá-los a importância do trabalho em equipe e da união. Para finalizar, em roda os estudantes realizaram a leitura dos registros anexados nos balões. Esse momento foi oportuno também para avaliar o aprendizado, bem como refletir sobre o uso de metodologias ativas na monitoria acadêmica, como também, permitiu um espaço para sugestões de aprimoramento para novas abordagens nas aulas.

\section{Considerações finais}

A monitoria enquanto programa de iniciação à docência oportuniza o desenvolvimento e aprimoramento acadêmico no ambiente universitário, permitindo ao estudante à aproximação do ofício de ser professor, sobretudo o desenvolvimento de competências e habilidades comunicacionais e sociais.

O uso de metodologias ativas para abordagem das temáticas em estudo oportunizou a construção efetiva do aprendizado coletivo, possibilitaram a troca de conhecimentos, de experiências e saberes que enriqueceram a formação acadêmica e profissional. A abordagem em roda e com o Team Based Learn possibilita o contato e a escuta ativa do outro, favorecendo a apreensão do conteúdo explorado por meio de um diálogo reflexivo não impositivo. Também é valido ressaltar o uso da rede social WhatsApp, que proporcionou um contato contínuo com os estudantes, sendo um espaço de aprendizado e esclarecimento de dúvidas.

Portando, estratégias pedagógicas inovadoras e criativas na monitoria, mostram-se oportunas no processo de apreensão do conhecimento, pois instiga a participação e o senso crítico-reflexivo dos estudantes, contribuindo para o processo formativo $\mathrm{e}$ humanização de cada participante.

\section{Referências}

1. Andrade, EGR; Rodrigues, ILA; Nogueira, LMV And Souza, DF. Contribuição da monitoria acadêmica para o processo ensino-aprendizagem na graduação em enfermagem. Rev Bras Enferm.2018;71(Supl4):1596-603.

2. Sobral. Universidade Estadual Vale do Acaraú. Guia do Aluno UVA: 1ạ Edição / Leiliane Silva de Aguiar, Igor Pimentel Gomes Fernandes Vieira, Rosa Meire Alves Guimarães (Orgs). Sobral: Edições UVA, 2017.

3. Brito, LS; Ribeiro, LS; Ulisses, LO; Ortiz, MFA and Whitaker, COM. Experiência de discentes de enfermagem em metodologias ativas na atividade de ensino docente. Rev baiana enferm.2017;31:1-8.

4. Sobral, Universidade Estadual Vale do Acaraú (UVA). Projeto Politico Pedagogico do curso de enfermagem.2018 
5. Melo, MCH and Cruz, GM. Roda deconversa:umapropostametodológicaparaacons truçãodeumespaçod diálogo no ensino médio. Revista Imagens da Educação. 2014;4(2):31-39.

6. Oliveira, BLCA; Lima, SF; Rodrigues, LS and Junior, GAP. Team-Based Learning como Forma de Aprendizagem Colaborativa e Sala de Aula Invertida com Centralidade nos Estudantes no Processo Ensino-Aprendizagem. Revista Brasileira de Educação Médica. 2018; 42 (4) : 86 95.

7. Junior, JBB and Albuquerque, OCP. Possibilidades para o uso do whatsapp na educação: análise de casos e estratégias pedagógicas. Revista Tecnologias na Educação. 2016,n/v.18:315-32.

8. Nascimento LC, Dantas IRO, Andrade RD, Mello DF.Genograma e ecomapa: contribuições da enfermagem brasileira. Texto Contexto Enferm, Florianópolis, 2014 Jan-Mar; 23(1): 21120.

9. Silva, RS; Paixão, GPN; Lins, DB; Jesus, RA And Pereira, A.Estudo de caso como uma estratégia de ensino na graduação: percepção dos graduandos em enfermagem. Rev Cuid. 2014; 5(1): 606-12.

\section{Endereço para Correspondência}

Universidade Estadual Vale do Acaraú - UVA

Av. da Universidade, 850 - Alto da Brasília,

Sobral - CE

CEP.: 62010-295

E-mail: williancarire123@gmail.com

Recebido em 22/10/2019

Aprovado em 24/05/2020

Publicado em 30/06/2020 